\title{
A liturgia penitencial a partir de Jl 2,12-18
}

The penitential liturgy from Jl 2: 12-18

Jane Maria Furghestti Lima

\section{Resumo}

J1 2,12-18 está inserido em um horizonte temático de uma liturgia penitencial, onde toda comunidade deve estar presente e expressar, por meio de ritos religiosos, seu pedido de ajuda a YHWH. Essa liturgia é realizada por meio de um culto, no templo de Jerusalém. Os sacerdotes, como liderança da comunidade, conduzem a oração de súplica e a comunidade com orações, e gestos seguem o ritual. Esta liturgia penitencial não apresenta sacrifícios ou ofertas materiais, no entanto, o próprio contexto de carência favorece o oferecimento "do coração", ou seja, uma doação da pessoa como um todo. O contexto de J1 2,12-18 é de uma catástrofe natural, que provoca a carestia e ausência dos produtos necessários para a subsistência. Em decorrência desta situação de crise, o povo de Judá-Jerusalém também vive uma condição de apatia espiritual. No entanto, ainda reside a esperança de que por meio de uma ação litúrgica penitencial se possa mudar este contexto desfavorável. O profeta, então, seguindo a convocação do próprio YHWH, interpela a comunidade para que, através de um ritual litúrgico, possa realizar o processo de retorno a Ele.

Palavras-Chave: Culto; Liturgia; Penitência; Salvação.

\section{Abstract}

Jl 2:12-18 is part of a thematic horizon of a penitential liturgy, where the whole community should be present and express through the liturgical 
rites their request for helping to YHWH. This liturgy is performed through a worship service, in the temple of Jerusalem. The priests, as leadership of the community, conduct the prayer of pleading and the community follows the ritual with prayers and gestures. This penitential liturgy has no sacrifices or material offerings, however, the own context of shortage promotes an offering of the heart, namely, a grant of the whole person. The context of J1 2:12-18 is about a natural catastrophe which causes famine and the absence of necessary products for the livelihood. As a consequence of the crisis the people of Juda-Jerusalem also envisage a state of spiritual apathy. Nevertheless there is still hope that through a penitential liturgical service this unfavorable context can be changed. Then the prophet, following the convocation of YHWH himself, summons the community so that through a liturgical rite can accomplish the process of returning to him.

Keywords: Worship; Liturgy; Penitence; Salvation.

\section{Introdução}

O pano de fundo do texto de J1 2,12-18 é de uma catástrofe natural. Este fenômeno provoca uma situação de carestia, assim como a falta dos produtos necessários para a subsistência. Tal crise origina uma reação de desânimo, que gera no povo de Judá-Jerusalém uma apatia espiritual. O profeta, então, seguindo a convocação de YHWH, interpela a comunidade para que esta possa fazer o processo de retorno a Ele. No discurso do profeta, vislumbra-se ainda uma esperança de que por meio de uma ação litúrgica penitencial, se possa mudar este contexto desfavorável.

Este trabalho visa apresentar e explicitar o desenvolvimento da liturgia penitencial em J1 2,12-18, e, partindo do estudo desta unidade textual, apontar elementos que possam ser relevantes nesta forma de oráculo na literatura profética. O presente estudo é fruto de uma abordagem mais ampla do tema "Voltai para mim e eu voltarei para vós: um estudo exegético de J1 2,12-18", elaborado originalmente como uma dissertação de mestrado. ${ }^{1}$

\footnotetext{
${ }^{1}$ FURGHESTTI LIMA, J. M. Voltai para mim e eu voltarei para vós: um estudo exegético de Jl 2,12-18. Dissertação de mestrado, Rio de Janeiro: PUC-Rio, 2013.
} 
E, portanto agora, ${ }^{2}$

Oráculo de YHWH:

"Voltai a mim com todo vosso coração,

com jejum, com lágrima e com lamento;

e rasgai vossos corações,

mas, não vossas vestes”.

Então, voltai para YHWH vosso Deus,

porque ele é gracioso e compassivo,

lento na ira e pleno de amor

e se compadece da desgraça.

Quem sabe, Ele volte,

e se compadeça,

e deixe, atrás de si, uma bênção,

oferta e libação para YHWH, vosso Deus.

Tocai uma trombeta em Sião,

santificai um jejum,

proclamai uma reunião,

congregai o povo,

santificai uma assembleia,

reuni anciãos,

congregai crianças e lactantes.

Que saia o noivo de seu recinto

e a noiva de seu aposento.

Entre o pórtico e o altar

chorem os sacerdotes,

ministros de $\mathrm{YHWH}$,

e digam:

Tem piedade YHWH de teu povo,

e não entregues tua herança à reprovação

para dominar contra eles nações. ${ }^{3}$

Por que dirão entre os povos:

“Onde está o seu Deus?"

Então, YHWH encheu-se de zelo por sua terra, e comoveu-se por seu povo.
$12 \mathrm{a}$

$12 \mathrm{~b}$

$12 \mathrm{c}$

$12 \mathrm{~d}$

$13 \mathrm{a}$

$13 \mathrm{~b}$

$13 \mathrm{c}$

$13 d$

$13 \mathrm{e}$

$13 \mathrm{f}$

$14 \mathrm{a}$

$14 \mathrm{~b}$

$14 \mathrm{c}$

$14 d$

$15 \mathrm{a}$

$15 \mathrm{~b}$

$15 \mathrm{c}$

$16 \mathrm{a}$

$16 \mathrm{~b}$

$16 \mathrm{c}$

$16 \mathrm{~d}$

$16 \mathrm{e}$

$16 f$

$17 \mathrm{a}$

$17 \mathrm{~b}$

$17 \mathrm{c}$

$17 \mathrm{~d}$

$17 \mathrm{e}$

$17 \mathrm{f}$

$17 \mathrm{~g}$

$18 \mathrm{a}$

$18 \mathrm{~b}$

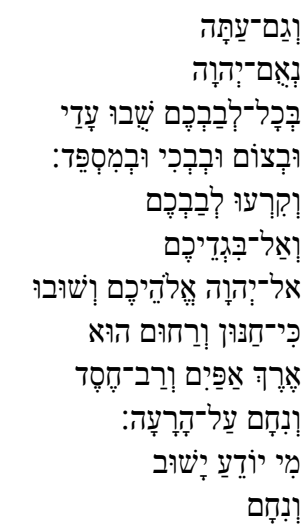

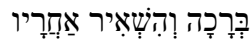

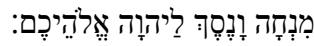

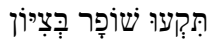

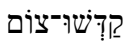

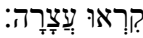

אִסְפוּ־עָּם

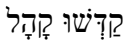

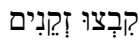

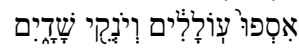

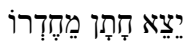

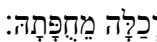

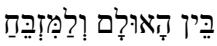

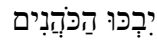

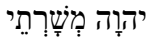

וְיאמְרוּוּ

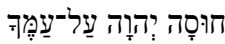

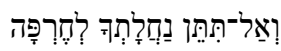

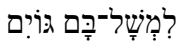

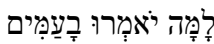

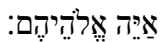

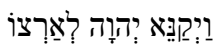

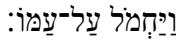

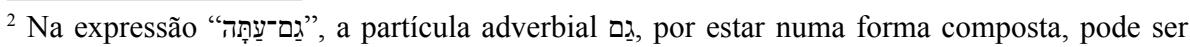
traduzida por "pois", "agora", "portanto", como em Gn 44,10; 1Sm 12,16 (cf. L. ALONSO SCHÖKEL, “גֵַ", DBHP, p. 141).

${ }^{3}$ Uma outra possível tradução do v. 17e poderia ser "para dominá-los nações". A tradução "para

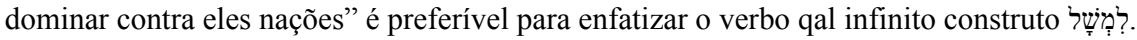


J1 2,12-18 está inserido em um horizonte temático de uma liturgia penitencial, na qual toda comunidade deve estar presente e expressar, por meio de ritos religiosos, seu pedido de ajuda a YHWH. Essa liturgia é realizada por meio de um culto, no templo de Jerusalém. Os sacerdotes, como líderes da comunidade, conduzem a oração de súplica e a comunidade, com orações e gestos, segue o ritual. Dado importante, neste contexto, é que a convocação feita pelo profeta é obedecida por todos os seguimentos da comunidade, inclusive os sacerdotes, os recém-casados, os idosos e os lactantes. Esta liturgia penitencial não apresenta sacrifícios ou ofertas materiais, pois o próprio contexto de carência favorece um oferecimento "do coração", ou seja, uma doação da pessoa como um todo.

O objeto único do culto, no livro de Joel, é o próprio YHWH, que não pode ser representado por imagens. É proibida toda forma de culto a homens e a animais, sendo desta forma um ato litúrgico centrado em YHWH (cf. Ex 20,4-6; 34,17; Gn 35,1-4). YHWH se mostra como o Senhor da vida, que implica na proibição de sacrifícios humanos (cf. Dt 12,31); igualmente é proibida a idolatria (cf. Ex 20,3; 23,24); a magia ou feitiçaria (cf. Ex 22,18; Dt 18,10-12); a adivinhação (cf. Lv 19,26); o culto aos mortos (cf. Lv 19,27ss); a mutilação ritual (cf. Dt 14,1) e a prostituição religiosa (cf. Dt 23,19). O culto a YHWH adquire, assim, um caráter moral e espiritual, que ocupa, na antiguidade, um lugar completamente à parte em relação aos demais cultos. Neste sentido, o culto como se estabelece na Aliança, necessita de uma disposição interior e de uma ação exterior. A organização do culto mosaico trouxe a necessidade da existência de ministros, de vestimentas apropriadas, de sacrifícios e de festas fixadas por um calendário e um espaço cultual materializado no templo de Jerusalém (cf. Ex 20,24; Dt 12,5). ${ }^{4}$

\section{O templo em Jerusalém}

O templo tem uma história significativa, pois, segundo a tradição bíblica, desde os patriarcas, a construção de um lugar de sacrifício já era suficiente para significar a existência de um santuário (cf. Gn 12,7.8; 13,18; 26,25; 33,20). O sacerdote era o ministro do altar, o sacrifício ritual principal do culto era a oferenda que seria levada ao altar. ${ }^{5}$ Assim, o altar se encontrava onde quer que se oferecesse um sacrifício, podendo ser inclusive temporário. ${ }^{6}$

\footnotetext{
${ }^{4}$ Cf. AUSEJO, S. "culto”. Diccionario de la Bíblia. Barcelona: Herder, 1964, p. 425-426.

${ }^{5}$ Cf. VAUX, R. de. Instituições de Israel no Antigo Testamento. São Paulo: Paulus, 2003, p. 444.

${ }^{6}$ Cf. MACKENZIE, J. L. “altar”. Dicionário Bíblico. São Paulo: Paulinas, 1984, p. 30.
} 
A raiz verbal da palavra מִנְָדָ (altar) significa originariamente "imolar" (זכח), mais tarde, ganha um sentido mais específico de "imolar com a intenção de um sacrifício". 7 Com a evolução ritual no templo, as vítimas eram imoladas fora do altar, para onde eram levadas posteriormente, exceto as aves. Neste espaço, também se encontravam as oferendas vegetais. A mesma palavra designa também o "altar do incenso", de onde se conclui que o altar é o lugar no qual se ofereciam sacrifícios de qualquer natureza. ${ }^{8}$ Algumas citações, que retratam as práticas religiosas, a ornamentação e a estrutura do templo podem ser encontradas em fragmentos dentro da literatura deuterocanônica (cf. 1Mac $1,21-24.45-46 ; 4,38-40){ }^{9}$

Para além das narrativas bíblicas é muito difícil determinar quando e que tipos de ofertas foram estabelecidas em Israel para uso no templo. O testemunho de alguns textos da literatura pós-exílica serve para evidenciar que tais ofertas eram usuais no segundo templo (cf. J1 1,9.13; 2,14; Ml 2,12; 3,3; $1 \mathrm{Cr}$ $29,21 ; 2 \mathrm{Cr} 29,35)$.

Entre as ofertas, que normalmente eram apresentadas no templo, havia a רִנְָחָה (cf. J1 14d), que tem origem em costumes seculares, como o presente dado a pessoas hierarquicamente superiores, especialmente reis, com objetivo de indicar uma atitude de respeito e submissão (cf. 1Rs 10,25; 2Rs 8,8-9; Is $39,1)$. No sentido religioso, מְִָָּ é uma oferta de cereais, mas que não exclui uma forma primitiva de oferta de animais (cf. Gn 4,4-5). ${ }^{10}$

A oferta da מִּזָדָ poderia ser feita em forma de cereal cru, ou tostado e esmagado, ou moído até virar farinha (cf. Nm 5,15.25), ou ainda transformado em pães ou bolos que eram assados no forno ou fritos em azeite. Incenso e sal também faziam parte da מִנְָָה , porém era proibido acrescentar fermento ou mel. A מִנְִחָה era oferecida todas as manhãs e todas as tardes, e consumida apenas pelos sacerdotes. Na maioria dos casos, a מִuְְָ era um complemento de um sacrifício sangrento, holocausto ou sacrifício de comunhão, e era acompanhado de uma libação de vinho. ${ }^{11}$ A oferta indicava uma submissão total

\footnotetext{
${ }^{7}$ Cf. ALONSO SCHÖKEL, L. "זכת". HARRIS, R. L.; ARCHER, Jr.; WALTKE, B. K. (eds.). Dicionário Internacional de Teologia do Antigo Testamento. São Paulo: Vida Nova, 1998, p. 188-189.

${ }^{8}$ Cf. VAUX, R. de. Instituições de Israel no Antigo Testamento, p. 444-445.

${ }^{9}$ Em 1Mc 4,44-51 é descrita: a demolição e a reconstrução de um novo altar dos holocaustos do templo, a restauração do lugar santo e o interior da morada, a santificação dos átrios e a fabricação de novos utensílios sagrados, que foram levados para o interior do santuário. Estas medidas se tornaram necessárias, uma vez que o templo havia sido profanado pelos estrangeiros.

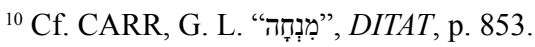

${ }^{11}$ Cf. VAUX, R. de. Instituições de Israel no Antigo Testamento, p. 459-460.
} 
pִ מִנְחָה era uma homenagem prestada a YHWH e tinha uma grande importância na

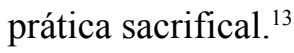

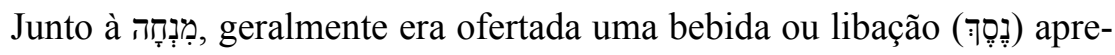
sentada com o holocausto (cf. Ex 29,40; Lv 23,13; Nm 15,1-10). Diariamente, uma libação deveria ser derramada sobre o altar do sacrifício ou aos seus pés (cf. Eclo 50,15). O líquido geralmente era o vinho (cf. Ex 29,40; Nm 15,5.7.10) ou uma bebida fermentada (cf. Nm 28,7), sabe-se também que água e azeite foram usados como libação (cf. $2 \mathrm{Sm} 23,16$; $1 \mathrm{Cr} 11,18$; Mq 6,7). ${ }^{14}$

No livro de Joel, o templo é apresentado como uma instituição valorizada e com uma importante função junto ao povo. Os ritos próprios de uma liturgia penitencial são aceitos como parte integrante do culto no templo. Os sacerdotes e os anciãos se reúnem no templo para responder ao apelo do profeta por uma convocação litúrgica, que envolve toda a comunidade. Diante da carência

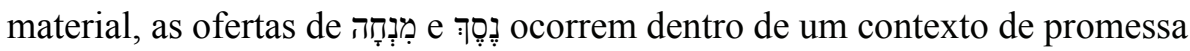
do retorno de YHWH para Judá-Jerusalém (cf. J1 2,14cd). Estas ofertas representam, na verdade, a perspectiva do retorno da prosperidade e da fecundidade da terra, que daria possibilidade do oferecimento regular das ofertas do culto.

\section{O sacerdote}

Entre as autoridades existentes em Judá-Jerusalém, os sacerdotes formavam o grupo responsável pelo culto. A presença de anciãos também é citada em Joel como um grupo valorizado dentro da comunidade. Destaca-se, no entanto, a figura do profeta como a "voz de YHWH" no meio do povo. No livro de Joel, o profeta é ouvido e obedecido por todos os segmentos da sociedade em seus oráculos e exortações. A figura do rei nunca é mencionada, e esta ausência sugere que o próprio YHWH seja reconhecido como soberano do povo de Judá-Jerusalém. O livro dá destaque à soberania divina, afastando qualquer tipo de usurpação de poder pelo governante humano.

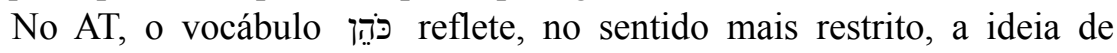
"ministro das coisas sagradas" especialmente dos sacrifícios (cf. Gn 14,18; Ex 18,12). ${ }^{15}$ Os sacerdotes deviam estabelecer um exemplo pessoal de santidade

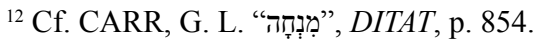

${ }^{13}$ Cf. PLEIN, I. W. Sacrificio e Culto no Israel do Antigo Testamento. São Paulo: Loyola, 2001, p. 77.

${ }^{14}$ Cf. WILSON, M. R. "נְק:", DITAT, p. 970-972.

${ }^{15}$ Cf. ALONSO SCHÖKEL, L. "פּדּה", Dicionário Bíblico Hebraico-Português. São Paulo: Paulus, 1977, p. 308.
} 
(cf. Dt 33,9); consultar a YHWH em seus oráculos e ensinar a lei (cf. Lv 10,11; Mq 3,11; Ml 2,7). Tais responsabilidades permitiam que o sacerdote também servisse ao povo como juiz (cf. Dt 17,9).

A tradição bíblica é explícita, quando afirma que antes da construção do primeiro templo de Jerusalém, os israelitas prestavam culto nos numerosos santuários espalhados pelo território (cf. $1 \mathrm{Sm} 1,1-4 ; 7,15-17)$. Cada um desses santuários era servido pelos seus próprios sacerdotes, hereditários, na maior parte dos casos.

Os sacerdotes exerciam as funções estabelecidas segundo a lei levítica, como a de oficiar oferendas e sacrifícios (cf. Lv 1-7), determinar quem tinha a lepra (cf. Lv 13-14), assim como, desempenhavam outras atividades rituais e sociais. Eles eram sustentados por doações e dízimos da agricultura (cf. Lv $10,12-15 ; 27,30-34)$. Parece que a função principal e, talvez mais antiga, dos sacerdotes era a bênção, algo que, em Joel, é pedido pelo profeta e realizado por YHWH na forma da prosperidade da terra (cf. Nm 6,23-26; J1 2,14). ${ }^{16}$

\section{O Yôm Kippur}

O yôm kippur é a referência mais próxima ao texto de $\mathrm{J1}$ 2,12-18, uma vez que, nesta solenidade, a maioria dos elementos litúrgicos da unidade textual está presente: a convocação de toda assembleia, a obrigatoriedade do jejum, os gestos exteriores. O yôm kippur exige uma penitência para todo o povo de Israel, celebrado de acordo com as disposições da lei, cada ano, no décimo dia do sétimo mês (cf. Lv 16; 23,26-32; Nm 29,7-11). No templo, somente o sumo sacerdote poderia oficiar e lhe era permitido entrar no Santo dos Santos com vestes sacerdotais simples. Colocando-se dois cabritos machos na entrada do templo, um deles era consagrado a YHWH e o outro para azazel (cf. Lv 16,26). Após confessar seus próprios pecados e os de sua casa, matava-se um novilho como sacrifício pelo pecado, entrava-se no Santo dos Santos e se queimava o incenso. Depois, o sacerdote sacrificava o cabrito consagrado a YHWH e, com seu sangue aspergia o Santo dos Santos. Então, colocava as duas mãos sobre a cabeça do segundo cabrito, confessava os pecados do povo e os "transferia" simbolicamente para o animal, expulsando-o então, para o deserto.

O yôm kippur é o único dia de jejum nacional prescrito na lei do AT. Apesar da legislação ter sido reelaborada no período exílico o rito com jejum, como tema principal, seria provavelmente pré-exílico. O pedido para jejuar neste dia é universal e seu caráter penitencial é reforçado pela expressão de

${ }^{16}$ Cf. McKENZIE, J. L. “altar”, Dicionário Bíblico, p. 816-818. 
“autoexpiação" (cf. Lv 16,29; 31,27.32; Nm 29,7). No período pré-exílico, provavelmente, existiram outros jejuns litúrgicos (cf. Jr 36,6) ${ }^{17}$.

No livro de Joel, a liturgia penitencial parte de uma grave crise nacional e de uma situação de carência e penúria vivida pelo povo (cf. J1 1,10-20). É uma liturgia extraordinária, ou seja, não está dentro do calendário litúrgico estabelecido. Além desta particularidade, percebe-se que a liturgia de Jl 2,12-18 apresenta elementos diversos das liturgias encontradas no AT: a) ela é convocada por um profeta e não pelos sacerdotes; b) todos devem participar, mesmo aqueles que poderiam ter algum tipo de dispensa; c) há ausência de ofertas para o templo, sejam elas de animais ou vegetais; d) mesmo não excluindo os gestos penitenciais comuns de tais liturgias, a ênfase se dá na mudança interior do indivíduo e da comunidade, fazendo destes a oferta de maior valor para YHWH. ${ }^{18}$

\section{As cerimônias matrimoniais}

O matrimônio no antigo Israel era considerado um contrato, no qual a mulher era propriedade do marido (cf. Ex 20,17). Este era chamado de baal, ou seja, o dono, que possuía todos os direitos sobre a mulher (cf. Ex 21,3.22; $2 \mathrm{Sm}$ $11,26 ; \operatorname{Pr} 12,4)$. O noivo era obrigado a entregar ao pai da noiva uma quantia em dinheiro, conhecida como מהַ (cf. Gn 34,12; Ex 22,16; 1Sm 18,25). A mulher ao casar deixava seus pais e habitava com seu marido, fazendo parte do seu clã, assim como seus filhos (cf. Gn 24, 58-59).

O matrimônio, geralmente, era prometido. Não existia, porém, um tempo estabelecido para a realização do casamento, podendo ser um tempo longo ou não (cf. Gn 24,67; 29,15-21). Um homem comprometido com uma mulher, mesmo sem estar casado com esta, estaria dispensado da guerra (cf. Dt 20,7; $24,5)$. No entanto, a cerimônia do matrimônio era considerada uma festividade particular que não tinha prioridade diante das festas e convocações públicas, como é o caso de $\mathrm{J} 12,16 .^{19}$

A preparação do matrimônio implicava uma série de gestos e rituais, como o corte do cabelo da noiva e o jejum dos noivos. A cerimônia principal era a da entrada da noiva na casa do noivo (cf. Ct 3,11; Is 61,10). Esta, ricamente vestida e adornada (cf. Sl 45,14.15; Is 61,10), coberta com um véu (cf. Ct 4,1.3; 6,7) não

\footnotetext{
${ }^{17}$ SMITH-CHRISTOPHER, D. L. "fasting”. In: FREEDMAN, D. N. (ed.). Eerdmans Dictionary of the Bible. Cambridge: Eerdmans Publishing Co., 2000, p. 456.

${ }^{18}$ No livro de Jonas, o jejum e os ritos penitenciais servem ao mesmo objetivo (cf. FERNANDES, L. A. Jonas. São Paulo: Paulinas, 2010, p. 18-19.39-40).

${ }^{19}$ Cf. VAUX, R. de. Instituições de Israel no Antigo Testamento, p. 55.
} 
se descobria até a câmara nupcial. Depois disto, celebrava-se um grande festim (cf. Jz 14,10; 7,14) que tinha duração de sete dias e poderia se prolongar até duas semanas (cf. Jz 14,12; Tb 8,20). ${ }^{20}$

No livro de Joel, noivo e noiva são retratados como se estivessem a caminho da realização de uma celebração matrimonial, saindo dos espaços reservados para o encontro nupcial e a condução para a casa do noivo. Bruscamente, a cerimônia é interrompida pela convocação penitencial, que neste caso, prescinde à celebração matrimonial particular. ${ }^{21}$ A consumação do matrimônio deverá ser adiada até que YHWH restitua a bênção sobre a terra, possibilitando, assim, os festins matrimoniais.

\section{Conclusão}

As orações, os lamentos e o jejum do povo são respondidos pela ação favorável de YHWH, que se mostra como a fonte da transformação social (cf. J1 2,18). ${ }^{22} \mathrm{O}$ convite para retornar a YHWH de todo o coração foi, de fato, aceito. A ação metafórica de rasgar os corações teve precedência sobre os gestos rituais de rasgar as vestes (cf. Jl 2,12). Desde modo, na resposta de YHWH, ficou concretizado que a mudança sincera do coração realizada pelo povo veio em primeiro lugar. A convocação para o retorno a YHWH foi acolhida pela comunidade e exercida pelos sacerdotes (cf. J1 2,15-17). A voz do profeta, que fez memória dos atributos divinos junto ao povo, ecoou dentro da comunidade (cf. Jl 2,13-14). Assim, cada segmento se reuniu em resposta uníssona e a oração de lamento chegou mais forte a YHWH.

J1 2,12-18 permite uma reflexão de temas importantes da tradição litúrgica judaica, como a relevância das ofertas do templo e o significado interior que tais gestos devem ter numa autêntica relação com YHWH. A verdadeira experiência religiosa está ligada ao retorno entendido como um encontro com o outro e a transformação da vida como um todo. Deste modo, J1 2,12-18 parece ter grande relevância para os estudos bíblicos veterotestamentários, no que se refere ao modo como o tema do retorno se encontra apresentado no livro de Joel e permite, também, abrir novas perspectivas de estudos posteriores com temáticas correlacionadas ao corpus dos Doze Profetas.

\footnotetext{
${ }^{20}$ Cf. VAUX, R. de. Instituições de Israel no Antigo Testamento, p. 56-57.

${ }^{21} \mathrm{Na}$ tradição bíblica existem exemplos de dispensa dos jovens esposos nas guerras durante o período de um ano (cf. Dt 20,7; 24,5).

${ }^{22}$ Cf. BIRCH, B. C. Hosea, Joel and Amos. Louisville: Westminster John Knox Press, 1997, p. 148.
} 


\section{Referências Bibliográficas}

ALONSO SCHÖKEL, L. Dicionário Bíblico Hebraico-Português. São Paulo: Paulus, 1977.

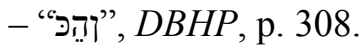

AUSEJO, S. Diccionario de la Biblia. Barcelona: Herder, 1964.

- "culto", p. 424-428.

BIRCH, B. C. Hosea, Joel and Amos. Louisville: Westminster John Knox Press, 1997.

DE VAUX, R. Instituições de Israel no Antigo Testamento. São Paulo: Paulus, 2003.

HARRIS, R. L.; ARCHER, Jr.; WALTKE, B. K. (ed.). Dicionário Internacional de Teologia do Antigo Testamento. São Paulo: Vida Nova, 1998.

- CARR, G. L., "מְִּדָדָ", DITAT, p. 853.

- WILSON, M. R., “"נְֶּ", DITAT, p. 970-972.

McKENZIE, J. L. Dicionário Bíblico. São Paulo: Paulinas, 1984.

- "altar", p. 30.

PLEIN, I. W. Sacrificio e Culto no Israel do Antigo Testamento. São Paulo: Loyola, 2001.

SMITH-CHRISTOPHER, D. L. "fasting”. In: FREEDMAN, D. N. (ed.). Eerdmans Dictionary of the Bible. Cambridge: Eerdmans Publishing Co., 2000, p. 456.

Jane Maria Furghestti Lima Mestre em Teologia pela PUC-Rio

Rio de Janeiro / RJ - Brasil

E-mail:jmariaf@hotmail.com

Recebido em: 01/06/13

Aprovada em: 09/05/14 